\title{
Developing and measuring healthcare capacity and quality in Burundi: LifeNet International's horizontal conversion franchise model
}

\author{
Michael F Brooks ${ }^{a}$, Maggie Ehrenfried ${ }^{b}$ \\ ${ }^{a}$ Communications Officer, LifeNet International, United States \\ ${ }^{\mathrm{b}}$ PT, DPT, Development Officer, LifeNet International, United States
}

\begin{abstract}
In a departure from traditional "vertical" healthcare interventions in low-resource settings that work to combat a single specific health issue, LifeNet International (LN) uses a horizontal conversion franchise to develop and measure healthcare capacity and quality in primarily faith-based health centers in East Africa. Through a comprehensive franchise package of Medical Training, Management Training, Pharmaceutical Supply, and Growth Financing, LN is able to leverage existing resources and respond to a greater number of the obstacles preventing facilities from providing quality care. Through its Quality Score Card, LN measures improvements in quality of care within its network. This tool has measured consistent and significant improvements in quality of care following LN partnership. Together, these services improve quality of care at East African primary care facilities in ways that issuespecific, "vertical" interventions cannot.
\end{abstract}

\section{Introduction}

In 2009, a US entrepreneur and franchise CEO began researching means of improving East Africa's pharmaceutical supply chain. He and his research team, however, quickly discovered that the most important missing component in the health care delivery supply chain was further upstream at the point of diagnosis and consultation. Through 3 years of continued research, trials, and pilots, the team launched LifeNet International's (LN) integrated franchise model, designed to build capacity and quality among primarily faith-based community health facilities in East Africa, which provide roughly $50 \%$ of healthcare in the region and
$12 \%$ in Burundi. ${ }^{1,2}$ As a model, the integrated LN franchise model was a departure from most international health interventions in Burundi and the broader region of East Africa. The purpose of this study is to highlight the difference between these models and inspect the impact LN's horizontal model has had on healthcare quality in Burundi. The fundamental differences between these opposing models are briefly discussed in the following definitions.

\section{Definitions: Vertical vs. Horizontal Models}

In the context of international development, a "Vertical" approach "may be considered to be 
disease-specific programs, the 'traditional' means by which governments, NGO's, international bodies, and donors work in many countries, partly as a means of limiting the problems of working through under-resourced health systems." ${ }^{1}$ A vertical model, therefore, is one that addresses a single issue or a specific need with a single, defined response. Examples include organizations working against malaria by distributing mosquito nets or overcoming lack of access to drinking water by drilling wells. Promoting family planning through condom distribution is another vertical response that remains popular today.

Frequently found in underdeveloped countries struggling with poverty and epidemics, vertical models are easier to pursue and advance in relative autonomy from local general health systems and other government structures, which are often poorly managed, under resourced, and suffering from limited human resources. ${ }^{2}$ For the vertical program, this has the benefit of focusing funding and avoiding complications with extensive integration of local structures. While these programs have seen success within a narrower goal framework, they can contribute to broader health issues, including the reduction of coordination with general health structures, skewing priorities from national priorities to funder priorities, diverting limited human resources from general and local health services, and creating inefficiencies through duplicate parallel operations. ${ }^{3}$

Horizontal models, in contrast, involve the broader health system of general services, including local primary care and its structures. Horizontal approaches integrate a wider range of solutions each designed to respond to a particular factor within a given issue. Examples of more horizontal models include anti-poverty campaigns that coordinate work with established government and private institutions, including a diverse set of responses to the various underlying factors directly linked to poverty. Most NGOs operate in between the theoretical definitions of vertical and horizontal models. Historically, however, NGOs tend towards a vertical model structure due to the complexities that increase as the number of services offered increases, in spite of the unintended consequences to the general horizontal systems. One of the most relevant unintended consequences was visible most recently in the lack of horizontal development, integration, and coordination in the response to West Africa's 2014 Ebola outbreak. This insufficiency in horizontal structures has been identified as a leading cause preventing effective responses to West Africa's 2014 Ebola outbreak. ${ }^{4}$

\section{Materials and methods}

\section{The Model}

The LN franchise model was built upon three years of research on the Burundi healthcare delivery system. This research identified key issues at all levels of healthcare delivery, most specifically at the level of consultation, diagnosis, and treatment. Based on these findings, the team recommended a systems-level approach for strengthening the underlying weaknesses instead of working vertically on one issue. LN's replicable, asset-light model designed for health system strengthening in response to identified weaknesses was based directly upon this recommendation. Findings by the team on the ground were consistent with contemporary publications beginning to investigate health systems strengthening, vertical vs. horizontal interventions, and their impact across a wide variety of health issues. ${ }^{5,6,7,8,9,10}$

LN's team identified a conversion franchise model as the best fit for strengthening healthcare systems as it provides scalable access to existing facilities and their operating structures in a way that meets needs both at the individual health centers as well as regional heath coordination needs. Conversion franchises have proven successful across a wide range of for-profit business applications, from fast food to software solutions, allowing existing business to partner with a larger organization and benefit from access to centralized resources and branding. In a healthcare context, LN 
is able to bring these same benefits to existing health structures in a way that has been recognized by the World Health Organization's Special Programme for Research and Training in Tropical Diseases as an innovation selected for research and international recognition. ${ }^{11}$ The final result in designing LN's model was the integrated franchise model built on four program verticals: Medical Training, Management Training, Pharmaceutical Supply, and Growth Financing.

LN Medical Training operates at the frontlines of local healthcare systems by delivering medical training directly to primary care nurses. This approach stresses knowledge transfer, behavior change, and local ownership. LN medical education experts work closely with LN's local nurse trainers, who then train staff at partner facilities once every month. The LN curriculum is designed for the local context in alignment with the priorities of the local Ministries of Health, as well as the international community's Millennium Development Goals and Post-2015 Development Agenda. The lesson plans cover best practices for addressing maternal, neonatal, and child health, HIV/AIDS, malaria, reproductive health, and more.

LN's Management Training program trains managerial staff at franchise partner health facilities in financial management and accounting, pharmacy and human resource management, key data analysis, and planning and budgeting. These skills help health centers avoid common stock-out problems, manage debt, and improve their financial sustainability.

Through LN's Pharmaceutical Supply program, LN connects rural partner health centers to local and regional wholesalers, delivering medicines directly to facilities. Before launching the program, LN research discovered that health center nurses were often purchasing medicines themselves, spending days at a time to travel to the capital cities by public transportation in order to buy whatever they could before returning. This cost them valuable time when they could have been providing care to patients. In addition to saving health center staffs time, LN's supply program also dramatically decreases the occurrence of stock-outs in partner pharmacies and increases the quality and variety of the medicines they offer. In countries with non-existent or ineffective quality assurance programs for imported or locally produced pharmaceuticals, LN tests medicines using its own mini-lab, working in coordination with other distributors to create a quality assurance apparatus operated by local personnel, ensuring the quality of pharmaceuticals distributed through the LN network.

Filling a gap in local capital markets, LN's Growth Financing loan program increases the scope of services health centers offer and the revenue they generate. By providing small to mid-sized loans to LN partners who have demonstrated good money management, LN finances projects that expand facilities' capacity and services. Partners are eligible to apply for loans once they have achieved LN's quality standards on key financial management lessons in the Management Training program. LN's “rent-to-own” program, operated under the aegis of Growth Financing, allows health centers to pay a small fraction of the market value of an item of medical equipment — such as an ultrasound machine or a glucometer - and rent the item from LN, eventually purchasing the item through the monthly installments. Once qualified for equipment financing by achieving financial management quality benchmarks, partner health centers can select equipment from a list according to their ability to repay. Because LN pairs equipment placement with ongoing medical training and check-ins, no equipment goes unused. Health centers generate more revenue when they offer expanded services made possible by additional equipment, which helps them improve their financial sustainability and stability. In 2015, LN sold 53 pieces of equipment to partner health centers in Burundi, generating over $\$ 16,000$ in new revenue for these facilities over the course of the year. 


\section{Quality Score Card}

LN measures the impact of its horizontal conversion franchise model over time through its Quality Score Card (QSC) evaluation tool. This tool is designed to measure both medical and management quality and was developed by LN nursing, public health, and development specialists, drawing on local Ministry of Health standards, the USAID/Smiling Sun Health Services "Quality and Monitoring Supervision Clinic Preparedness Guide," the IFC Self-Assessment Guide for Health Care Organizations from the Joint Commission International, the Management Sciences for Health Financial Management Assessment Tool, the Columbia University Access Project Health Center Assessment Tool, and other similar sources. $^{12,13,14,15,16,17}$ Directly aligned with the LN training curriculum, the medical and management QSCs measure standards set by the local Ministries of Health and then measure important additional items to quantify staff adherence to LN-taught best practices in healthcare delivery and management.

At the beginning of $\mathrm{LN}$ partnership, each health facility is evaluated by a LN monitoring and evaluation specialist. These specialists are drawn from program staff in the medical and management training teams, including experienced $\mathrm{LN}$ trainers as well as medical and management training program managers. The baseline evaluation score serves both as a control for LN's impact as well as a guide for the focus of the training and mentorship for each medical and management module.

LN monitors the implementation of the work plan through 1-year or 2-year contracts signed with partner health facilities. Contracts are signed by the LN Country Director, the health facility manager, and the leadership of the church or larger body to which the health facility belongs.

Regular training and mentorship reports from monthly site visits facilitate LN data collection. Each LN medical and management trainer writes a training report on every monthly visit. This report serves to confirm that each health facility is benefiting from regular monthly trainings and is progressing through the curriculum. It also serves to highlight particular challenges to be addressed or successes to be acknowledged.

At the end of each completed six-month medical and management module, health facility partners are re-evaluated with the QSC. The evaluation is conducted by one of LN's monitoring and evaluation specialists. In order to ensure objectivity, the monitoring and evaluation specialist is never a regular trainer at the site $\mathrm{s} / \mathrm{he}$ is evaluating. These scores are measured against the baseline score to measure the impact of $\mathrm{LN}$ intervention.

With the implementation of these quality improvement and measurement tools, LN began working towards its goal to transform quality of care for underserved populations in East Africa.

\section{Results}

In 2012, LN implemented its conversion franchise model with its first cohort (group of health centers beginning partnership with LN in the same month). Through 2013, LN steadily increased the number of health centers within its network (Figure 1). While adding additional partnerships, LN terminated partnerships with some existing partner facilities that did not attend or otherwise participate in scheduled trainings, most noticeably in Q2 2012 and Q3 2013. This helped focus program interventions where facility leadership and staff were motivated and interested in leveraging the LN franchise package for improvements in quality of care. Along with a growing number of partner facilities, the number of patient visits in the franchise network (Figure 2) and the quality of care delivered within the network (Figure 3) also grew. Gains made by new cohorts followed similar patterns of growth and improvement. By the end of 2013, the network had grown from 10 to 41 franchise partners, delivering double the quality of care for over 60,000 patient visits per month. 
FIGURE 1: NUMBER OF HEALTH CENTERS WITHIN THE LN NETWORK

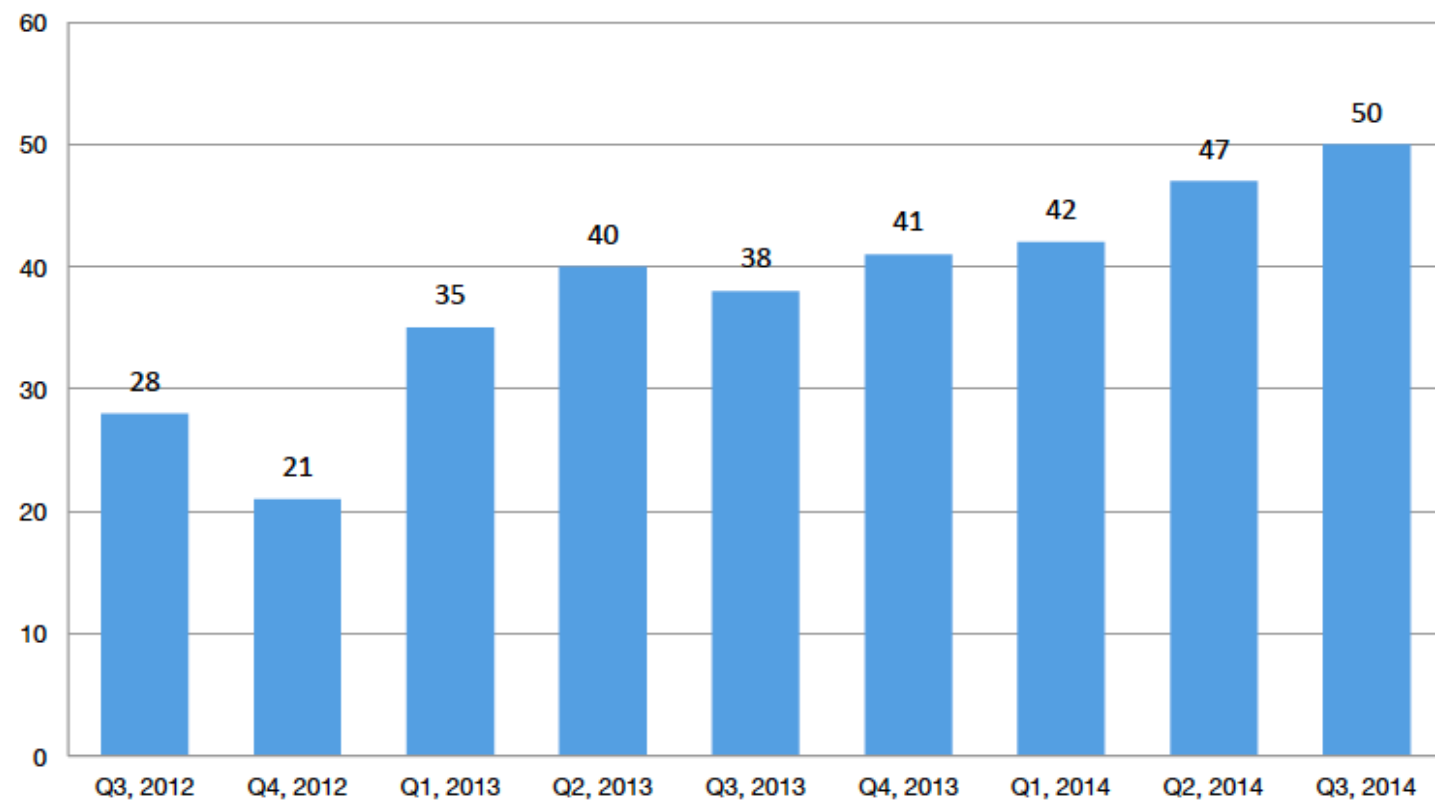

FigURE 2: NUMBER OF PATIENT VISITS IN THE LN NETWORK*

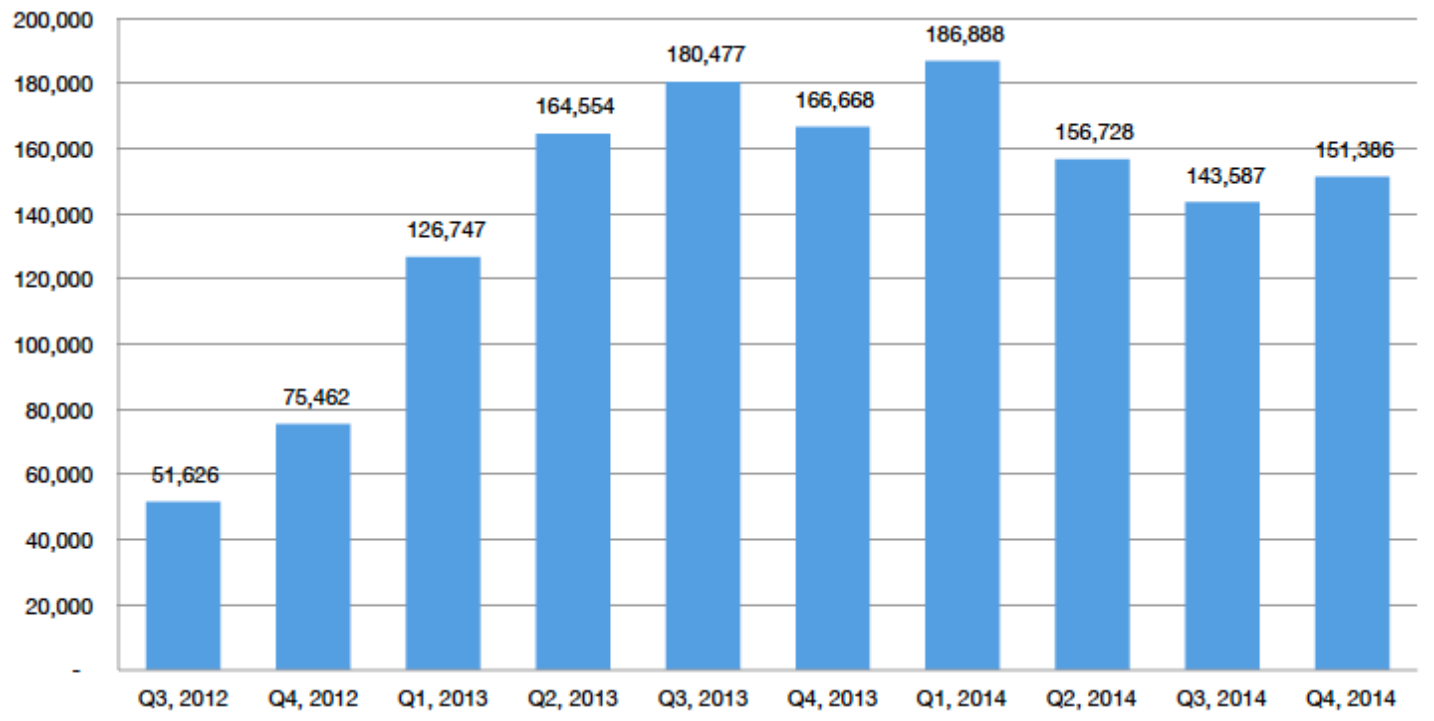

\footnotetext{
* The decrease in numbers after Q1 2014 is due to a restructuring in patient visit data collection that reduced redundancies. Health centers report information and statistics that must be sorted to ensure that one patient receiving multiple services from the health center is not counted multiple times. 
FiguRE 3: PERCENT INCREASE IN QUALITY OF CARE

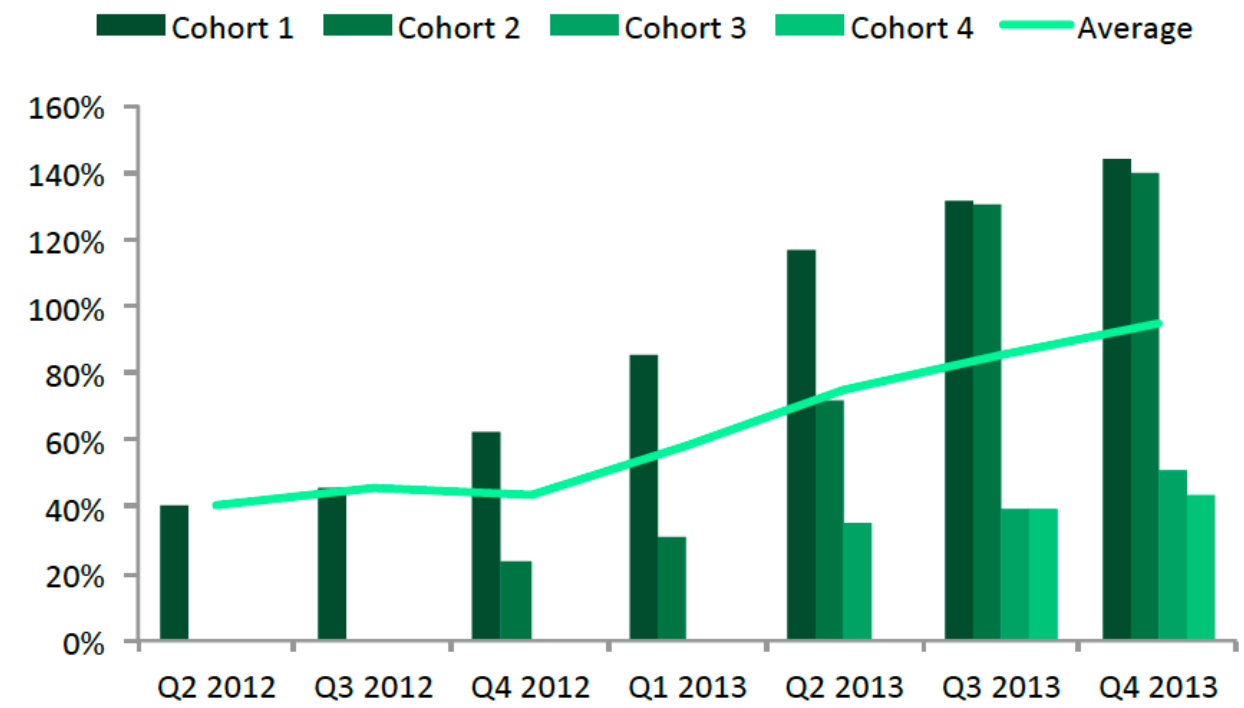

Beginning in 2014, LN implemented an updated Quality Score Card (QSC). Although similar to the original, it added multiple new levels of detail and precision. The most substantial change was the separation of management quality-related data points from the medical quality data points, creating separate medical and management QSCs in order to independently monitor LN's separate Medical Training and Management Training programs.

The number of health centers within the LN franchise network in Burundi continued to grow to 50 in Q3 2014, before reaching 60 partner centers by the end of 2015. (Figure 1) The number of patient visits within this growing network has grown consistently (Figure 2). In 2014, however, LN improved the way in which patient-visits were counted, reducing redundancies for patients that received separate treatments for different conditions during the same visit. This improvement in data collection is the driver behind the decrease in patient visits numbers during 2014.

Since the QSC update in 2014, LN no longer measures progress by cohort. Rather, LN measures progress within the LN curriculum. Improvements as a percent increase remained consistent, however, across both designations of measurement (cohort vs. progress in LN curriculum). Quality of care improvement has also remained consistent in both medical and management portions of the QSC (Figures 4 and 5). Since 2012, baseline QSC scores have been low in every area of care at all partner health centers. Within the first quarters of program implementation, however, partner health centers began to show significant improvement. 
FiguRE 4: 2015 MedicAl BASELINE AND FOLLOW-UP QSCS, By MOdULE $\uparrow$

Module I

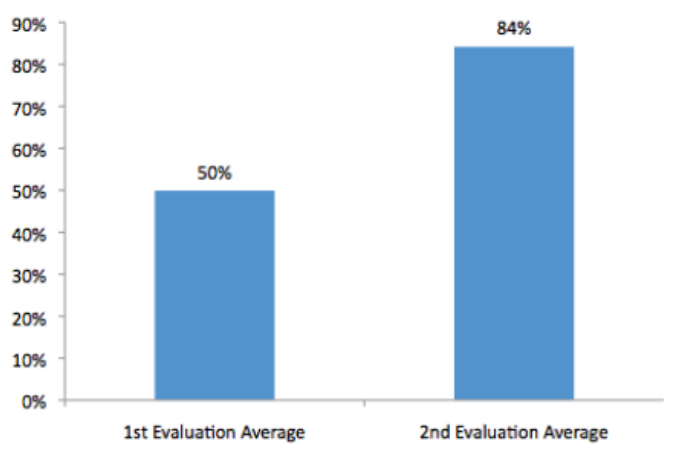

Module II

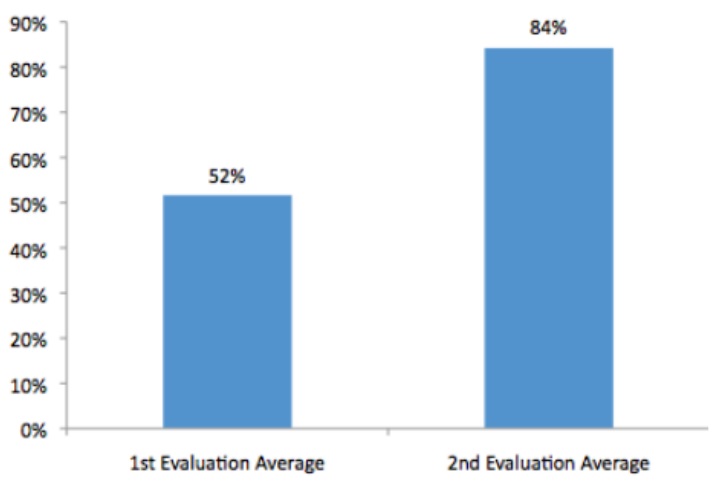

FIGURE 5: 2015 MANAGEMENT BASELINE AND FOLLOW-UP QSCS, By MOdULE \$

\section{Module I}

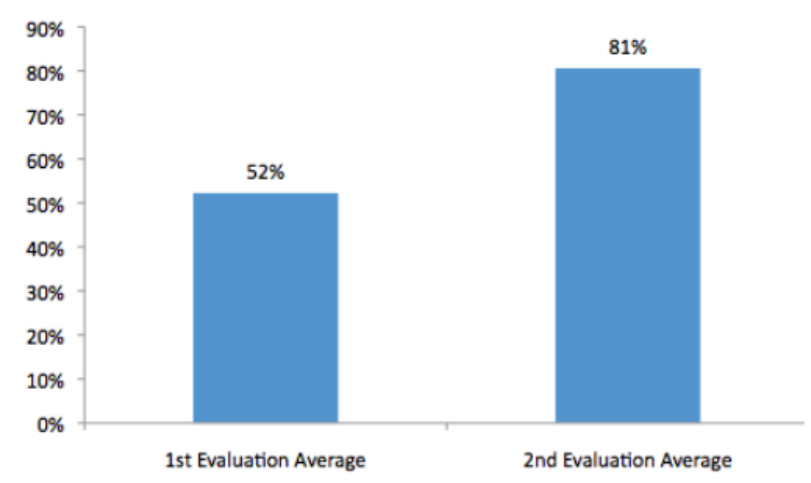

Module II

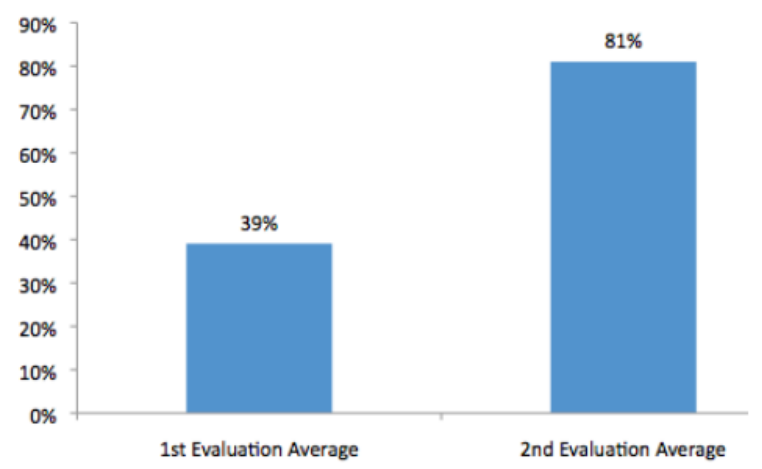

\footnotetext{
${ }^{\dagger}$ Module 1 in the LN medical curriculum trains medical staffs in everyday tasks including sanitation, consultation basics, infection prevention, and other core elements of primary care delivery. Module II covers primary care techniques specific to maternal health

* Module 1 in the LN Management Training curriculum trains management staffs in professional ethics, financial management, and pharmacy management. Module II continues with additional lessons on financial management, pharmacy management, and human resource management best practices

Nov 2016. Christian Journal for Global Health, 3(2):49-59. 
By comparing LN QSC score changes over time against Burundi Ministry of Health $(\mathrm{MOH})$ score changes over the same time (Figure 6), LN can help control for internal testing bias. Here, LN's QSC results remained extremely close to the Burundi MOH's own quality evaluations over the same period. This corroborates LN measurements and reflects the heavy emphasis $\mathrm{LN}$ places on aligning training curriculum with $\mathrm{MOH}$ priorities. The Burundi $\mathrm{MOH}$ quality evaluation tool is embedded into the LN QSC. Roughly 50\% of LN QSC metrics come from the $\mathrm{MOH}$ quality evaluation tool. The half of the LN QSC that is drawn independently from the $\mathrm{MOH}$ quality evaluation tool adds layers of specificity and detail that are not present in the government tool. This enables LN evaluations to track quality changes in levels of greater detail that is not possible in the $\mathrm{MOH}$ tool.

Because $50 \%$ of the LN QSC corresponds directly to the $\mathrm{MOH}$ evaluation tool, there should be a correlation between improvements at facilities when measured by both tools over similar time periods during $\mathrm{LN}$ intervention. Divergences introduced by the dissimilar 50\% in the LN QSC, differences in evaluator scoring, and other differentiating factors should introduce noticeable differences between the two measurement tools. With an average divergence of $5.63 \%$ in the preintervention measurements and $4.91 \%$ in the postintervention measurements, these divergences are smaller than expected. Differences between scores diverge by as much as $19.20 \%$ pre-intervention and $14.45 \%$ post-intervention, which are closer to what was originally expected. The extreme similarity in score averages (differences of only $1.60 \%$ preintervention and $0.63 \%$ post-intervention) are likely more attributable to coincidence than to the $50 \%$ correlation between scoring tools and methodologies. Once full 2014 data becomes available, the difference between $\mathrm{MOH}$ and $\mathrm{LN}$ scoring will again be comparable and allow for more accurate analysis of results.

FiguRE 6: LN QSC SCORES VS. BuRUNDI MOH SCORES (2013)

\begin{tabular}{lcccc}
\hline Province & $\begin{array}{l}\text { Pre-Intervention: Average } \\
\text { MOH Score }\end{array}$ & $\begin{array}{l}\text { Pre-Intervention: LN } \\
\text { QSC Average Score }\end{array}$ & $\begin{array}{l}\text { Post-Intervention: Average } \\
\text { MOH Score }\end{array}$ & $\begin{array}{l}\text { Post-Intervention: LN } \\
\text { QSC Average Score }\end{array}$ \\
\hline Buja Mairie & 60.61 & 60.37 & 71.55 & 76.58 \\
Buja Rural & 65.70 & 59.30 & 84.18 & 80.70 \\
Bururi & 46.47 & 65.67 & 77.52 & 80.17 \\
Cibitoke & 70.03 & 64.96 & 81.91 & 79.01 \\
Gitega & 64.70 & 63.30 & 81.73 & 82.47 \\
Kayanza & 73.46 & 72.15 & 83.78 & 84.47 \\
Kirundo & 64.10 & 58.61 & 79.67 & 74.38 \\
Makamba & 64.39 & 68.41 & 78.97 & 81.79 \\
Muramvya & 54.77 & 51.34 & 74.11 & 59.66 \\
Muyinga & 73.06 & 72.23 & 83.29 & 76.18 \\
Mwaro & 52.76 & 60.76 & 75.65 & 83.00 \\
Rutana & 67.81 & 79.97 & 79.01 & 85.39 \\
Avg & $\mathbf{6 3 . 1 6}$ & $\mathbf{6 4 . 7 6}$ & $\mathbf{7 9 . 2 8}$ & $\mathbf{7 8 . 6 5}$ \\
\hline
\end{tabular}

Nov 2016. Christian Journal for Global Health, 3(2):49-59. 


\section{Discussion}

LN's horizontal model has been successful in improving quality of care within its network of primarily faith-based health centers. By integrating multiple responses to the numerous barriers to quality care, LN addresses not only the medical conditions of poor care but also the underlying factors including financial management, sustainability, and access to pharmaceuticals and equipment.

This intervention style avoids the issues associated with vertical models. By training workers in the general health system instead of redistributing them according to vertical priorities, LN interventions strengthen local systems instead of weakening them. By aligning training curriculums with $\mathrm{MOH}$ priorities, LN avoids skewing intervention priorities away from national health agendas. This also avoids contributing to poor communications and coordination with general health structures. And, by equipping management staff to improve reporting, LN improves national statistics and other records supplied by health centers to the centralized government health systems.

The greatest impact factors for this horizontal approach are its comprehensive impact, its scalability, and its adaptability. By working through medical and management training, pharmaceutical supply, and financing programs, $\mathrm{LN}$ is able to affect change at every level of health center operations, raising the level of all aspects of health care delivery. The conversion franchise model allows quick scalability without compromising impact. With a core curriculum in place, the model is adaptable to areas with similar health systems and struggles. Since launching in Burundi, LN has successfully expanded its franchise to Uganda and the Democratic Republic of the Congo, making adjustments in its curriculum for each country to align with its specific health needs and $\mathrm{MOH}$ priorities.
Although a horizontal model allows for the most comprehensive, wide-reaching impact at the primary care facility level, it also creates demands and challenges not present in vertical models. With the expansion of intervention areas across different specialties (e.g., medical, health management, credit and financing, import/export, and pharmaceuticals), horizontally oriented organizations like LN must incorporate specialists that ensure the correct operation of each program as well as its proper integration with the others. By maintaining a sufficiently skilled staff, however, this challenge is reduced and programs work well in coordination with each other.

One major challenge upon entry for $\mathrm{LN}$ was communicating the model to health centers in a way that created interest and buy-in. With no offers of per-diems or other immediate financial incentives, facilities were less interested. Once trainings began and the facilities saw the benefits of training and partnership, however, their hesitancy was replaced with ongoing interest and, mostly by word of mouth, they communicated their good experiences to other facilities that, in turn, became interested in LN partnership without LN having to work to "sell" or "pitch" the partnership and franchise model.

LN continues to mine and evaluate data in order to measure impact and assess the effectiveness of current programs. Current data suggest that LN's integrated horizontal model is effective in improving quality of care in Burundi. Data from new operations in Uganda and the DRC will enable direct contrast and comparison between changes in quality of care from country to country, permitting new analysis for the transferability of the model across countries in the region. In Burundi, and potentially across the region, the LN horizontal model is able to address diverse barriers to quality care that would not be possible to address in a vertical model.

\section{References}

1. Olivier J, Tsimpo C, Gemignani R, Shojo M,

Coulombe H, Dimmock, F, et al. Understanding the roles 
of faith-based health-care providers in Africa: review of the evidence with a focus on magnitude, reach, cost, and satisfaction. The Lancet. 2015;386(10005):1765-75. http://dx.doi.org/10.1016/50140-6736(15)60251-3

2. Woodward D, Smith RD; WHO. Global public goods and health: concepts and issues. Available from: http://www.who.int/trade/distance_learning/gpgh/gpgh1/ en/index11.html

3. Elzinga G. Vertical-horizontal synergy of the health workforce; WHO. Available From: http://www.who.int/bulletin/volumes/83/4/editorial10405 len/

4. Primary Health Care Performance Initiative [Methodology Note]. Available from:

http://www.phcperformanceinitiative.org/sites/default/fil es/phcpi methodology note 0.pdf Published 2015 Sept.

5. Woodward D, Smith RD; WHO. Global public goods and health: concepts and issues. Available from: http://www.who.int/trade/distance_learning/gpgh/gpgh1/ en/index11.html

6. Knippenberg R, Lawn J, Darmstadt G, Begkoyian G, Fogstad H, Walelign N, et al. Systematic scaling up of neonatal care in countries. The Lancet.

2005;365(9464):1087-98.

http://dx.doi.org/10.1016/S0140-6736(05)74233-1

7. Rosenfield A, Min CJ, Freedman LP. Making Motherhood Safe in Developing Countries. N Engl J Med. 2007;356(14):1395-7. http://dx.doi.org/10.1056/NEJMp078026

8. Béhague DP, Storeng KT. Collapsing the verticalhorizontal divide: an ethnographic study of evidencebased policymaking in maternal health. Am J Public Health. 2008;98(4):644-9. http://dx.doi.org/10.2105/AJPH,2007.123117
9. Kieny M-P, Evans DB, Schmetsa G, Kadandalea S. Health-system resilience: reflections on the Ebola crisis in western Africa. Health-system resilience: reflections on the Ebola crisis in Western Africa. Available from: http://www.who.int/bulletin/volumes/92/12/14149278.pdf

10. WHO. Toolkit for assessing health-system capacity for crisis management. Available from:

http://www.euro.who.int/_data/assets/pdf_file/0008/157 886/e96187.pdf

11. Kieny M-P. Ebola and health systems: now is the time for change. World Health Organization. 2014 Dec 12. Available from:

http://www.who.int/mediacentre/commentaries/healthsystems-ebola/en/

12. WHO. 24 healthcare delivery innovations selected for research and international recognition. 2015 June 3. Available from:

http://www.who.int/tdr/news/2015/25_healthcare_deliver y_innovations/en/

13. USAID/Smiling Sun Health Services. Quality \& monitoring supervision clinic preparedness guide. 2010 January.

14. Management Sciences for Health. The financial management assessment tool. 2015.

15. Mango's financial management health check: how healthy is your NGO? 2005;2.0

16. Access Project, Columbia University. Questionnaire for evaluation of management capabilities in health centers.

17. International Finance Corporation. A self-assessment guide for health care organizations: March 2015.

Peer Reviewed

Competing Interests: None declared.

Nov 2016. Christian Journal for Global Health, 3(2):49-59. 
Correspondence: Michael F Brooks, LifeNet International, United States. mbrooks@Ininternational.org Maggie Ehrenfried, LifeNet International, United States. mehrenfried@Ininternational.org

Cite this article as: Brooks FM, Ehrenfried M. Developing and measuring healthcare capacity and quality in Burundi: LifeNet International's horizontal conversion franchise model. Christian Journal for Global Health (Nov 2016), 3(2): 49-59.

(C) Brooks FM, Ehrenfried M. This is an open-access article distributed under the terms of the Creative Commons Attribution License, which permits unrestricted use, distribution, and reproduction in any medium, provided the original author and source are properly cited. To view a copy of the license, visit http://creativecommons.org/licenses/by/4.0/

$$
\text { www.cjgh.org }
$$

Nov 2016. Christian Journal for Global Health, 3(2):49-59. 